\title{
Fixation of a Distal Diaphyseal Tibia Fracture with Neurovascular Tissue Incarceration: Surgical Technique Using a Lesser Invasive Approach
}

\author{
Wilson Belaieff, Dennis Dominguez and Axel Gamulin* \\ Division of Orthopaedic and Trauma Surgery, Department of Surgery, University Hospitals of Geneva, Switzerland
}

*Corresponding author: Axel Gamulin, MD, Division of Orthopaedic and Trauma Surgery, University Hospitals of Geneva, 4 Rue Gabrielle-Perret-Gentil, CH-1211 Geneva 14, Switzerland, Tel: +41-22-372-78-14, Fax: +41-22-372-77-99, E-mail: Axel.Gamulin@hcuge.ch

\begin{abstract}
Soft tissue incarceration in a distal diaphyseal tibia fracture may predispose to adverse fracture healing. Incarcerated soft tissue may include nerves and/or vessels, with the potential for neurovascular complications. Meticulous neurovascular examination of the extremity is mandatory, and, when in doubt, Doppler ultrasound of the fracture area should be obtained, in addition to computed tomography angiography if neurovascular structures are involved. In order to address this situation, a surgical technique combining the advantages of minimally invasive plate osteosynthesis and limited fracture line exposition is described, exemplified with the case of a $65 \mathrm{y} / \mathrm{o}$ male who sustained a low-energy right closed distal diaphyseal tibio-peroneal fracture (AO/ OTA type 42-B2) with anterior tibial artery and deep peroneal nerve entrapment.
\end{abstract}

\section{Keywords}

Distal diaphyseal tibia fracture, Neurovascular entrapment, Soft tissue incarceration, ORIF, MIPO

\section{Introduction}

Soft tissue interposition between fracture fragments may prevent bone union $[1,2]$. The incidence of this condition in distal diaphyseal tibia fractures is currently unknown but may be partly responsible for the reported delayed union rate of $4 \%-44 \%$ and non-union rate of $3.6 \%$ 9\% [3-8]. Anterior Tibial Artery (ATA) and Deep Peroneal Nerve (DPN) entrapments have been described in these fractures [9-11].

Bone healing depends on several paramount pre- requisites adequate construct stability (absolute vs. relative depending on the fixation method chosen), proper bone-to-bone contact and preserved local biology [12]. In order to achieve these goals, distal diaphyseal tibia fractures have historically been managed by Open Reduction and Internal Fixation (ORIF), Intramedullary Nailing (IMN) and more recently by Minimally Invasive Plate Osteosynthesis (MIPO) [13]. MIPO is a soft-tissue sparing technique with minimal local bone biology disruption, thereby limiting the surgical stress on the bone healing process. It relies on indirect reduction principles and does not allow direct fracture visualization. This may be problematic in case of soft tissue interposition at the fracture site, where a formal ORIF technique is usually performed to free incarcerated structures, with the major disadvantage of causing additional soft tissue damage, devascularization and periosteal stripping that may compromise successful bone healing [14].

The authors describe a lesser invasive surgical technique to address this situation combining a limited exposure of the fracture site to release the incarcerated soft tissue, followed by MIPO of the distal tibia.

\section{Case Presentation}

The use of this approach is exemplified with the case of a 65-year-old male, smoker and chronic alcohol abuser, who sustained a low-energy closed distal diaphyseal tibio-peroneal fracture on the right side (AO/OTA type 42-B2; Figure 1). Right unilateral absent

Citation: Belaieff W, Dominguez D, Gamulin A (2017) Fixation of a Distal Diaphyseal Tibia Fracture with Neurovascular Tissue Incarceration: Surgical Technique Using a Lesser Invasive Approach. Trauma Cases Rev 3:054. doi.org/10.23937/2469-5777/1510054

Received: May 17, 2017; Accepted: July 17, 2017: Published: July 19, 2017

Copyright: (c) 2017 Belaieff W, et al. This is an open-access article distributed under the terms of the Creative Commons Attribution License, which permits unrestricted use, distribution, and reproduction in any medium, provided the original author and source are credited. 


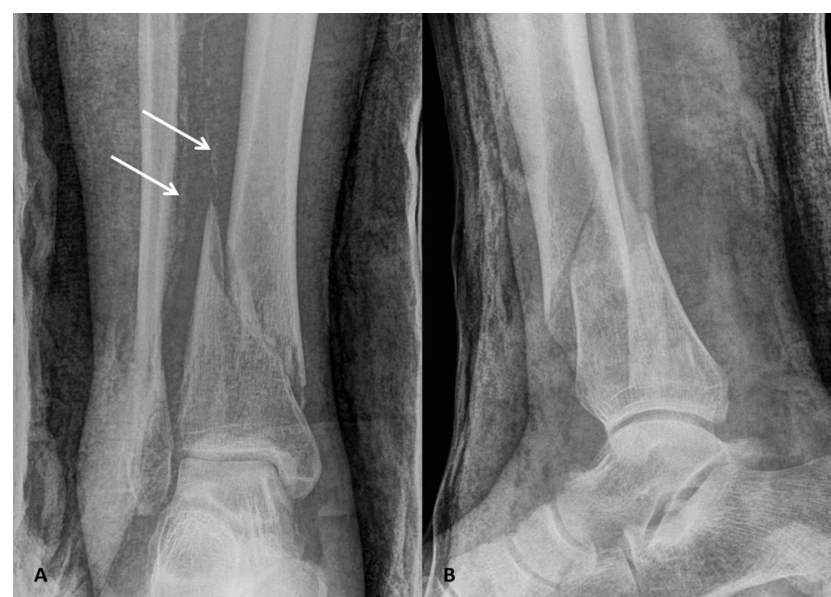

Figure 1: Plain anteroposterior $(A)$ and lateral $(B)$ radiographic views showing a right distal spiroid diaphyseal tibia fracture (AO/OTA type 42-B2) associated with a comminuted distal fibula fracture. Arrows indicate diffuse calcifications of infra-popliteal vessels.

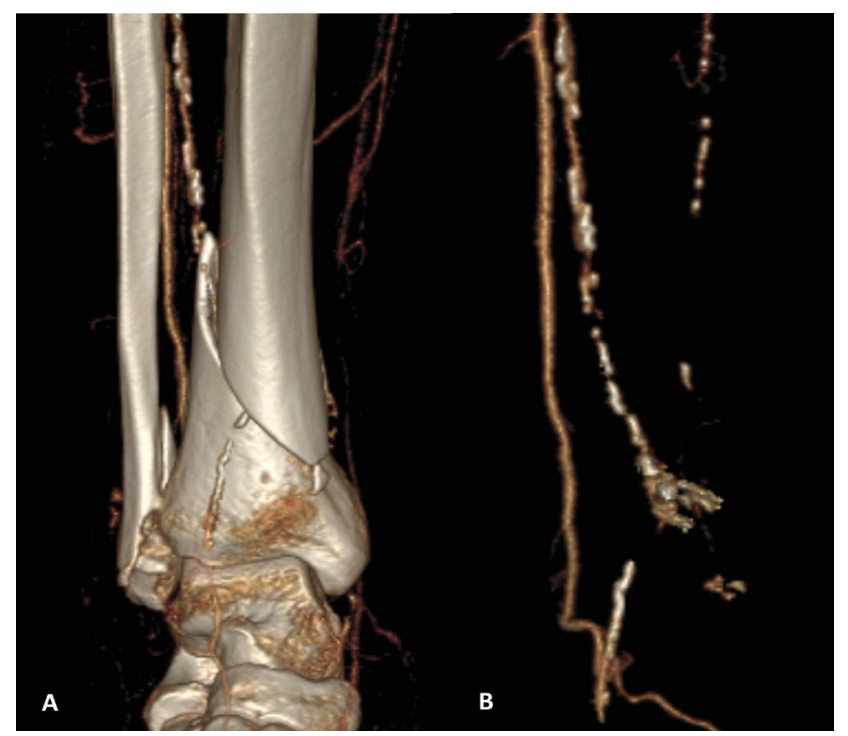

Figure 2: Three-dimensional reconstructed computed tomography angiography images of the arterial vessels of the right leg, with $(A)$ and without $(B)$ the underlying skeleton, showing diffuse atherosclerotic disease and anterior tibial artery entrapment with an arterial stop at the distal tibia fracture line, and distal reperfusion from collaterals.

pedal pulse was noted upon admission, with normal distal skin perfusion and preserved DPN function. On the contralateral non-injured extremity, pedal pulse was felt on palpation, distal skin perfusion was normal, as well as DPN function. Posterior tibial pulses were present bilaterally and compartments of the leg were soft and non-tender. Diffuse calcifications of all infra-popliteal vessels were visible on plain radiographic views (Figure 1). The absent pedal pulse motivated a Computed Tomography Angiography (CTA) that confirmed diffuse atherosclerotic disease as well as ATA entrapment at the fracture gap: vascular flow was interrupted at a kink over the bony prominences of the fracture and distal reperfusion was noted from functional collaterals (Figure 2).

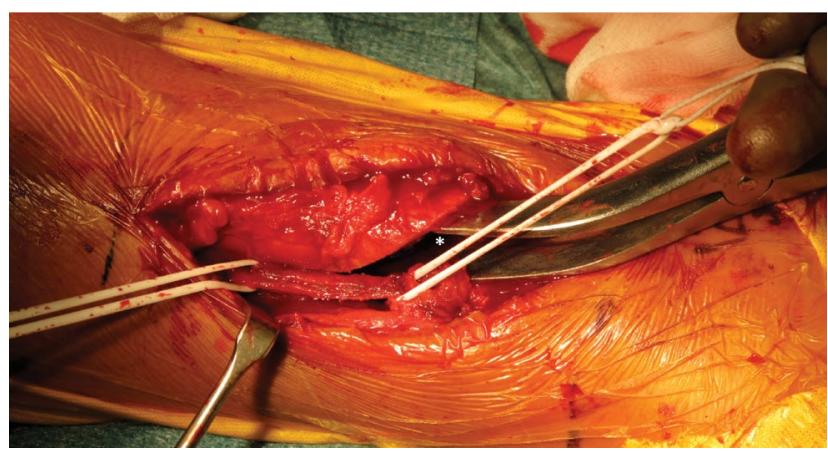

Figure 3: Clinical photograph at the time of surgery showing the use of a laminar spreader $\left({ }^{*}\right)$ distracting the fracture gap; the anterior tibial artery and deep peroneal nerve are isolated on silastic loops.

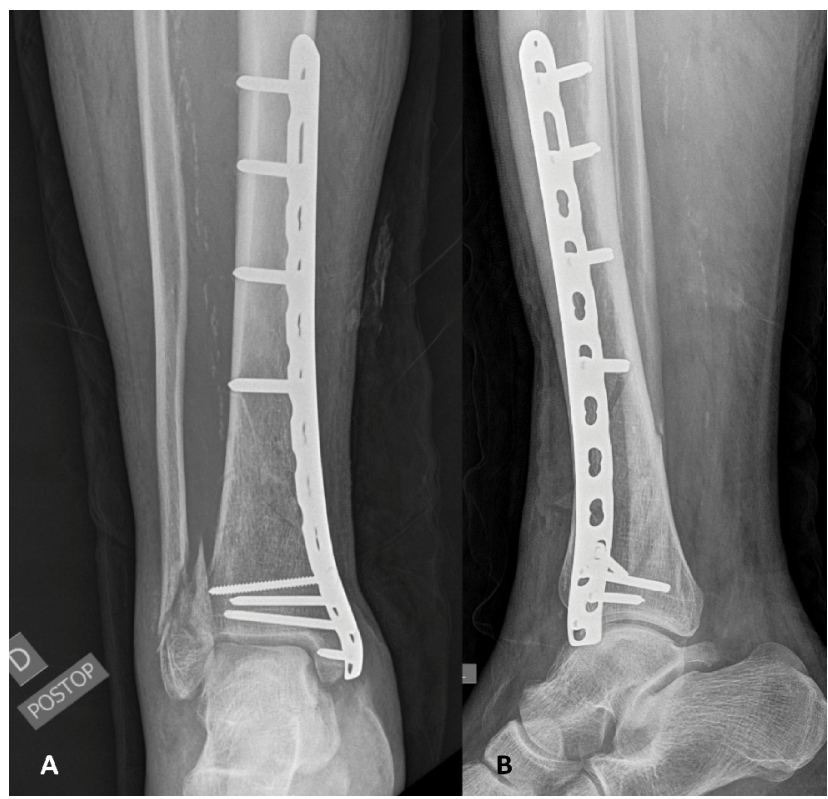

Figure 4: Plain anteroposterior $(A)$ and lateral $(B)$ radiographic views following distal tibia fixation revealing adequate reduction.

\section{Surgical Technique}

The surgical strategy involved three distinctive steps. The first step was performed within 24 hours after the injury and consisted of a $6 \mathrm{~cm}$ anterolateral incision centered on the fracture, to allow direct visualization of the fracture line. A laminar spreader was cautiously used to open the fracture gap, allowing identification of entrapped tissues including periosteum, ATA, concomitant veins and DPN. These structures were removed from the fracture without further periosteal stripping (Figure 3). Visual examination after release revealed no gross injury to the ATA and DPN, so that no microsurgical exploration or repair was needed.

The second step consisted of the diaphyseal tibia fracture fixation using a standard MIPO technique. A 3 $\mathrm{cm}$ incision above the medial malleolus was made and a low profile anatomically pre-contoured $3.5 / 4.5 \mathrm{~mm}$ locking compression plate (LCP; Synthes ${ }^{\circledR}$, Oberdorf, Switzerland) was subcutaneously inserted in a retro- 
grade fashion. A $3 \mathrm{~cm}$ medial incision was made over the proximal end of the plate, $2 \mathrm{~cm}$ posteriorly to the anterior crest of the tibia. Reduction was obtained indirectly with manual traction of the limb under fluoroscopic guidance and confirmed by direct visualization through the anterolateral incision. After provisional fixation with $1.6 \mathrm{~mm}$ Kirschner wires, the plate was fixed proximally and distally with the appropriate locking screws. Due to swollen soft tissues over the lateral malleolus and poor skin quality, distal fibular fixation was postponed. The surgical wounds were closed and dressed in the customary manner. Upon operating room discharge, the foot was well perfused and pedal pulse was present on the operated side. Postoperative radiographs showed adequate fracture reduction (Figure 4).

On Day 13, the third step was performed with lateral malleolus fracture fixation using an anatomic 2.7/3.5 mm LCP (Synthes ${ }^{\circledR}$, Oberdorf, Switzerland). Toe touch weight-bearing with a short leg cast was prescribed for 6 weeks following surgery.

\section{Results}

Postoperative radiographs showed adequate fracture reduction. Wound healing occurred uneventfully. The patient was full weight bearing at 12 weeks and radiographs confirmed ongoing bone union at 16 weeks (Figure 5). At time of last follow-up, at 12 months, the patient was pain-free, active and ambulating, and radiographs showed complete bone union (Figure 6). Pedal pulse was present throughout follow-up and the patient had no complaints suggestive of vascular insufficiency of the affected limb. DPN function was preserved. Ankle range of motion reached a flexion-extension of $45-0-5^{\circ}$ at last follow-up after intensive physiotherapy.

\section{Discussion}

Soft tissue interposition in a fracture line is associ-

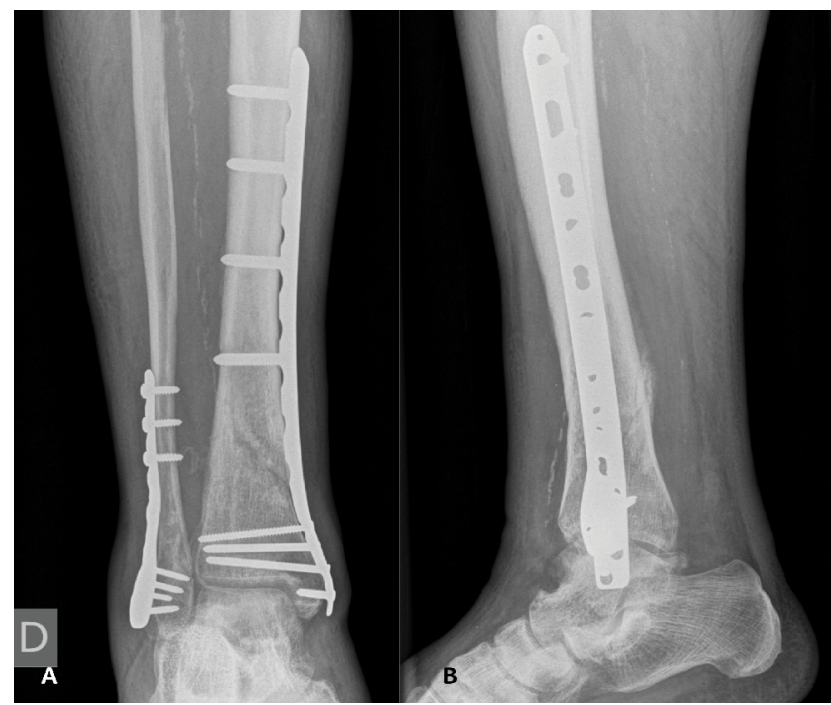

Figure 5: Plain anteroposterior $(A)$ and lateral $(B)$ radiographic views 16 weeks after definitive osteosynthesis demonstrating ongoing fracture consolidation. ated with fracture reduction difficulties, non-operative treatment failure, injury to the incarcerated structure and compromised bone union [1,2,9-11,15-21]. Experimental studies show that muscle interposition in an animal fracture model prevents callus formation by creating a gap at the fracture site and is a predictable way to obtain intentional non-union [1,2,20,21]. In the human model, fractures treated conservatively may evolve towards non-union more frequently than those surgically fixed partly due to unrecognized loss of proper bone-tobone contact [16]. In the distal part of the leg, the tibialis anterior, extensor digitorum longus, and extensor hallucis longus muscles and tendons lie at an average of $6 \mathrm{~mm}$ from the anterior distal tibial surface, the closest being the tibialis anterior making this structure at particular risk [22]. The incidence of adverse bone healing due to soft-tissue interposition in distal tibia fractures is currently unknown. However, this mechanism may be partly responsible for the delayed union and non-union rates of $4 \%-44 \%$ and $3.6-9 \%$ respectively reported despite adequate fixation methods [3-8,23].

Vascular entrapment may additionally occur and create unfavorable local conditions for proper bone healing. The ATA and DPN lie at a mean distance of 3 $\mathrm{mm}$ from the anterior tibial cortex, making these neurovascular structures at risk of entrapment [22,24]. The ATA and the posterior tibial artery form a rich anastomotic arterial network supplying the external third of the distal tibial diaphysis [25]. Injury to this vascular supply is significantly more prevalent during ORIF than during MIPO and results in slower bone healing process, increased risk of delayed union, non-union, osteomyelitis and chronic vascular insufficiency, and may lead to higher amputation rates [14,25-27]. However, there is no evidence supporting vascular repair in distal tibia

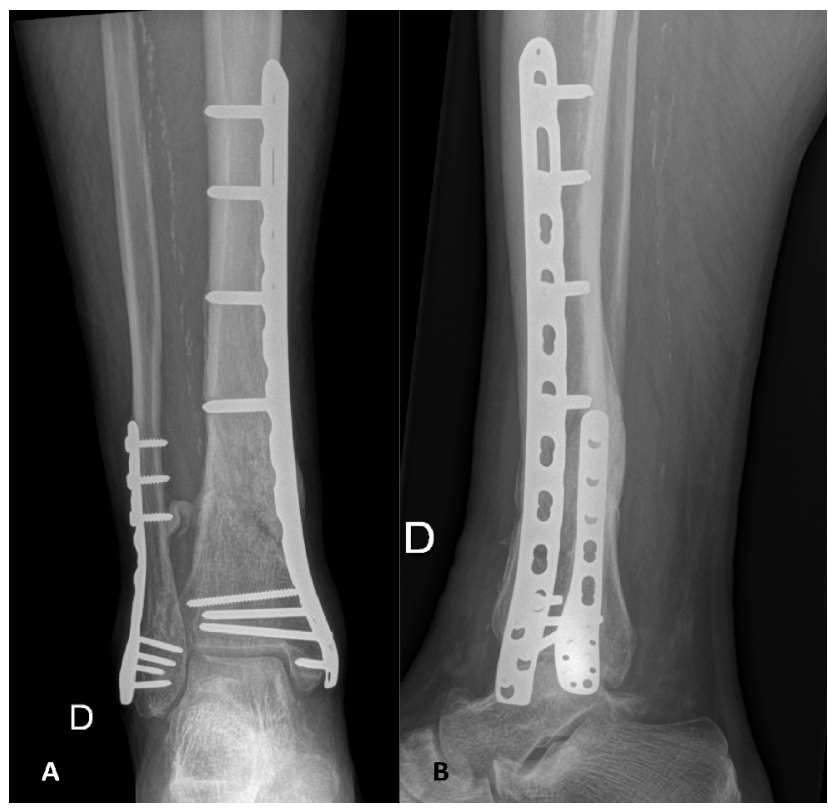

Figure 6: Plain anteroposterior $(A)$ and lateral $(B)$ radiographic views 1 year after osteosynthesis showing complete fracture consolidation. 
fractures with concomitant infra-popliteal arterial injuries in the absence of acute limb ischemia $[28,29]$.

Soft tissue entrapment recognition may be arduous. Meticulous neurovascular examination of the extremity is mandatory. Doppler-ultrasound may be useful to identify dorsalis pedis pulse when marked local swelling is present or in obese patients. Ultrasound is a low-cost and non-invasive examination which is accessible to most trauma centers and may help in diagnose incarcerated soft tissue in the fracture line with $86.3 \%$ specificity and $96.9 \%$ sensitivity [30]. Magnetic resonance imaging may not be available in all centers, nor be cost-effective if routinely performed [31]. The authors recommend that Doppler-ultrasound of the fracture area be obtained when confronted with suspected soft tissue incarceration in a distal tibia fracture, in addition to CTA when neurovascular structures are involved.

There are currently only two cases of ATA entrapment in an adult distal tibia fracture reported in the literature, as well as one series of distal tibial epiphyseal growth-plate fractures in children [9-11]. However, none of these publications reported on fracture healing and patient outcome. The case described in the present paper seems therefore valuable for the orthopaedic trauma community by supporting the feasibility of the hybrid approach we present, when encountering a similar clinical situation.

To the best of our knowledge, this is the first time a hybrid technique associating a limited exposure of the fracture site and minimally invasive percutaneous plating of the distal tibia is described. This technique promotes the advantage of minimally disrupting the local bone vascularization as well as giving direct access to the fracture site in order to release the entrapped structures. Avoidance of periostal stripping should be emphasized during the approach. This technical note is also the first report on an entrapped ATA being disincarcerated within 24 hours after injury. This ability to proceed early into surgery is a major advantage in order to prevent further ongoing entrapment-related damage to the neurovascular bundle.

\section{Conclusion}

Soft tissue incarceration in distal diaphyseal tibia fracture is detrimental to bone union. Its incidence is currently unknown but may be an underestimated cause of adverse fracture healing despite adequate fracture fixation. Meticulous neurovascular examination of the extremity is mandatory, and, when in doubt, Doppler ultrasound of the fracture area should be obtained, in addition to CTA if neurovascular structures are involved. According to current evidence in terms of union rates and reported complications, we believe that MIPO should be preferred over ORIF to fix distal diaphyseal tibia fractures not amenable to IMN [32-39]. However, this technique should be adapted when facing soft tissue structures incarcerated in the fracture gap as exemplified in this report.

The lesser invasive approach we describe is an effective and simple surgical technique with minimal local biology disruption.

\section{Ethical Statement}

\section{Ethical approval}

All procedures performed in studies involving human participants were in accordance with the ethical standards of the institutional and/or national research committee and with the 1964 Helsinki declaration and its later amendments or comparable ethical standards. Informed consent was obtained from all individual participants included in the study.

\section{Conflict of interest and source of funding}

There are no financial and personal relationships with other people or organisations that could inappropriately influence (bias) this work. There was no external source of funding or financial support for this study.

\section{References}

1. Petroianu A, Corsetti RA, Alberti LR (2004) The effect of the presence of muscle tissue in a bone healing site. Rev Hosp Clin Fac Med Sao Paulo 59: 193-197.

2. Altner PC, Grana L, Gordon M (1975) An experimental study on the significance of muscle tissue interposition on fracture healing. Clin Orthop Relat Res 269-273.

3. Gaebler C, Berger U, Schandelmaier P, Greitbauer M, Schauwecker $\mathrm{HH}$, et al. (2001) Rates and odds ratios for complications in closed and open tibial fractures treated with unreamed, small diameter tibial nails: a multicenter analysis of 467 cases. J Orthop Trauma 15: 415-423.

4. Karladani AH, Granhed H, Kärrholm J, Styf J (2001) The influence of fracture etiology and type on fracture healing: a review of 104 consecutive tibial shaft fractures. Arch Orthop Trauma Surg 121: 325-328.

5. Papakostidis C, Kanakaris NK, Pretel J, Faour O, Morell DJ, et al. (2011) Prevalence of complications of open tibial shaft fractures stratified as per the Gustilo-Anderson classification. Injury 42: 1408-1415.

6. Phieffer LS, Goulet JA (2006) Delayed unions of the tibia. Instr Course Lect 55: 389-401.

7. Sitnik AA, Beletsky AV (2013) Minimally invasive percutaneous plate fixation of tibia fractures: results in 80 patients. Clin Orthop Relat Res 471: 2783-2789.

8. Terver S, Miazzolo N, Hery JY (2005) Prospective and retrospective study of complications after centromedullary nailing of weight-bearing bones (CECOP study). Rev Chir Orthop Reparatrice Appar Mot 91: S155-S182.

9. Grace DL (1983) Irreducible fracture-separations of the distal tibial epiphysis. J Bone Joint Surg Br 65: 160-162.

10. Labler L, Wedler V, Mica L, Trentz O (2006) Entrapment of the anterior tibial artery in a distal tibial fracture after intramedullary nailing. Unfallchirurg 109: 156-159.

11. Miki RA, Lawrence JP, Gillon TJ, Lawrence BD, Zell RA (2008) Anterior tibial artery and deep peroneal nerve entrapment in spiral distal third tibia fracture. Orthopedics 31. 
12. Marsell R, Einhorn TA (2011) The biology of fracture healing. Injury 42: 551-555.

13. White RR, Babikian GM (2001) Tibia: shaft. In: Rüedi TP, Murphy WM, AO principles of fracture management. Thieme, Stuttgart, Germany, 523-540.

14. Borrelli J Jr, Prickett W, Song E, Becker D, Ricci W (2002) Extraosseous blood supply of the tibia and the effects of different plating techniques: a human cadaveric study. $J$ Orthop Trauma 16: 691-695.

15. Coonrad RW, Bugg El Jr (1954) Trapping of the posterior tibial tendon and interposition of soft tissue in severe fractures about the ankle joint. J Bone Joint Surg Am 36: 744750

16. Van der Linden W, Larsson K (1979) Plate fixation versus conservative treatment of tibial shaft fractures. A randomized trial. J Bone Joint Surg Am 61: 873-878.

17. Archibeck MJ, Scott SM, Peters CL (1997) Brachialis muscle entrapment in displaced supracondylar humerus fractures: a technique of closed reduction and report of initial results. J Pediatr Orthop 17: 298-302.

18. De la Caffinière JY, Bex M, Rengeval JP (1986) [Pseudarthrosis of the lower end of the radius due to interposition of the long extensor of the thumb]. Rev Chir Orthop Reparatrice Appar Mot 72: 505-508.

19. Jones GL, McCluskey GM 3rd, Curd DT (2000) Nonunion of the fractured clavicle: evaluation, etiology, and treatment. J South Orthop Assoc 9: 43-54.

20. Fujita M, Matsui N, Tsunoda M, Saura R (1998) Establishment of a non-union model using muscle interposition without osteotomy in rats. Kobe J Med Sci 44: 217-233.

21. Narang R, Laskin DM (1976) Experimental osteogenesis at fracture sites and gaps. J Oral Surg 34: 225-231.

22. Ali AA, Gregory JJ, Ockenden M, Hill SO, Makwana NK (2012) Anatomic description of the distal tibia: implications for internal fixation. J Foot Ankle Surg 51: 296-298.

23. Borg T, Larsson S, Lindsjö U (2004) Percutaneous plating of distal tibial fractures. Preliminary results in 21 patients. Injury 35: 608-614.

24. Wolinsky P, Lee M (2008) The distal approach for anterolateral plate fixation of the tibia: an anatomic study. J Orthop Trauma 22: 404-407.

25. Dickson K, Katzman S, Delgado E, Contreras D (1994) Delayed unions and nonunions of open tibial fractures. Correlation with arteriography results. Clin Orthop Relat Res 189-193.
26. Arany L, Baranyai T, Mândi A, Kunkli F (1980) Arteriographic studies in delayed-union and non-union of fracture. Radiol Diagn (Berl) 21: 673-681.

27. Brinker MR, Bailey DE Jr (1997) Fracture healing in tibia fractures with an associated vascular injury. J Trauma 42: 11-19.

28. Segal D, Brenner M, Gorczyca J (1987) Tibial fracture with infrapopliteal arterial injuries. J Orthop Trauma 1: 160-169.

29. Shah DM, Corson JD, Karmody AM, Fortune JB, Leather RP (1988) Optimal management of tibial arterial trauma. J Trauma 28: 228-234.

30. Tukenmez M, Percin S, Arslan M, Tezeren G (2006) Use of ultrasound for diagnosis of interposition of soft tissue in bone fracture line. Ultrasound Med Biol 32: 197-200.

31. Raman S, Wallace EC (2011) MRI diagnosis of trapped periosteum following incomplete closed reduction of distal tibial Salter-Harris II fracture. Pediatr Radiol 41: 1591-1594.

32. Adam P, Bonnomet F, Ehlinger M (2012) Advantage and limitations of a minimally-invasive approach and early weight bearing in the treatment of tibial shaft fractures with locking plates. Orthop Traumatol Surg Res 98: 564-569.

33. Collinge C, Protzman R (2010) Outcomes of minimally invasive plate osteosynthesis for metaphyseal distal tibia fractures. J Orthop Trauma 24: 24-29.

34. Hasenboehler E, Rikli D, Babst R (2007) Locking compression plate with minimally invasive plate osteosynthesis in diaphyseal and distal tibial fracture: a retrospective study of 32 patients. Injury 38: $365-370$.

35. Hazarika S, Chakravarthy J, Cooper J (2006) Minimally invasive locking plate osteosynthesis for fractures of the distal tibia--results in 20 patients. Injury 37: 877-887.

36. Helfet DL, Shonnard PY, Levine D, Borrelli J Jr (1997) Minimally invasive plate osteosynthesis of distal fractures of the tibia. Injury 28: S42-S47.

37. Mirza A, Moriarty AM, Probe RA, Ellis TJ (2010) Percutaneous plating of the distal tibia and fibula: risk of injury to the saphenous and superficial peroneal nerves. J Orthop Trauma 24: 495-498

38. Redfern DJ, Syed SU, Davies SJ (2004) Fractures of the distal tibia: minimally invasive plate osteosynthesis. Injury 35: $615-620$

39. Zelle BA, Bhandari M, Espiritu M, Koval KJ, Zlowodzki M, et al. (2006) Treatment of distal tibia fractures without articular involvement: a systematic review of 1125 fractures. J Orthop Trauma 20: 76-79. 